\title{
Photography of Papyri and Ostraca
}

This paper is based on many years of experience with photography of papyri and ostraca. Since 1970 I have regularly photographed papyri both for my own work and that of others, using a variety of cameras and techniques. At the beginning, I used $35 \mathrm{~mm}$ black-and-white film, but during my doctoral studies in UCL I graduated to $4 \times 5$ inch sheet-film which remained my favorite medium until digital photography became good enough to be applied.

I am not a professionally trained photographer, but have followed courses ${ }^{1}$ and worked in professional environments, not least in London where, for one year, I took care of all the photography for the Oxyrhynchus Papyri edition. ${ }^{2}$ For several years I took part in the missions for the AIP photographic archive in Cairo, and later I photographed ostraca during excavations of Mons Claudianus 1987-1993 and all the excavations in the Eastern Desert under the project Les praesidia du Désert Oriental, from 1994 to the present. ${ }^{3}$

What can be read in the following pages is thus based on the experiences of a practical field photographer, rather than of a scientist working in a laboratory. Equally, it is meant more for the benefit of papyrological colleagues than for scientists working on "imaging".

\section{The Problem}

Whether the object is a papyrus, an ostracon, or a wooden tablet with writing in ink, the problem is basically that of legibility. 2000 years in the ground have left their mark on these originals and they are nearly always discolored and the ink will often have faded, most often because of water. Besides, the writing may be obscured by dirt or salt-incrustations.

Stone-inscriptions and wax tablets present different problems inasmuch as they are incised. This will be dealt with later.

I begin with a summary of the types of problems that the photographer will encounter. The list will necessarily contain words and concepts that will only be defined later in this paper.

1 Notably a course of applied technical photography given by P. B. Schimdt, Skovshoved, in 1970.

2 This took place in the Central Photographic Unit, University College London, for one day a week in 1972-1973 under the leadership of Mr. Eric Hitchcock.

3 Directed by Hélène Cuvigny, and financed partly by Ministère des affaires étrangères, partly by Institut français d'archéologie orientale, Cairo. 


\subsection{Types of Papyri: Normal Brownish and Carbonized}

Papyri are flat, two-dimensional, objects and from a photographic point of view they are treated like ordinary reproductions. They need even, flat light. The background color will mostly be brownish and the ink, if it is a carbon-ink, will be black. All such papyri will respond to the standard-treatment, either a color photograph or a blackand-white, if necessary with some red-filtering. They will normally respond well to infrared.

Papyri written with metallic, ferro-gallic ink, which is often brownish, are much more difficult since the ink also responds to lightening of red and brown and may disappear, or at least not be improved under infrared treatment.

Carbonized papyri are much more difficult and do not all present the same problem. Some are just vaguely discolored while others are almost totally black, so that the ink is hardly visible. Some respond well to infrared others almost not. Some are under glass which makes it very difficult to do anything with them. Others again, especially those that have been unrolled by the Piaggio-method, ${ }^{4}$ are so brittle and warped that they must be treated as three-dimensional with the added consideration of depth of field.

Common to most papyri is that they are often mounted under glass. In most cases this does not bother the photographer if he positions his lights at an angle of $45^{\circ}$ to the surface and can avoid the problem of a reflection of the camera in the glass. ${ }^{5}$ If photographing papyri under glass, be sure to look for the reflection of overhead light. This is easily missed when you are concentrating on the papyrus under the lens, but the white spot may ruin the whole photo.

\subsection{Types of Ostraca: Limestone, Calcareous Clay, Brownish Clay}

Ostraca from the Pharaonic period are often written on limestone flakes, i. e. on a totally white background. If the ink is well preserved, it should make for a good photo. If the ink is rubbed or otherwise damaged there is no help in infrared and generally little that can be done to save the text. The same is true of ostraca written on whitish ceramics.

Ostraca on brown ceramics, written with black carbon-ink, are common in the Greco-Roman period and make up the large majority of those found in the Eastern Desert. If they are badly darkened, they can be quite forbidding at first sight, but, like

4 See Sider 2009, 307-308.

5 This depends on the presence of extraneous light and the amount of silver or chrome on the front of the camera. If the problem persists, it may be necessary to cut a hole in a sheet of black carton and place this in front of the camera, so that only the lens opening is visible. In any case, avoid more light than strictly necessary falling on the camera, the photographer or wherever, outside of the object. 
most papyri, they respond very well to red filtering and infrared treatment. The black ink will stay black on the photograph, but the reddish background can be lightened and the contrast thus enhanced.

\subsection{Wood, Parchment}

Both wood and parchment normally respond well to red or infrared procedure. When dealing with parchment, it is further advisable to consider the use of ultraviolet fluorescence, see Section 6, below. This method does not work on papyri and ostraca, and I have had little occasion to use it. Since the method further demands a special ultraviolet light-source (e. g., a so-called Wood's lamp) and a darkened room, it can be difficult to use under primitive conditions.

\subsection{Types of Ink: Red, Carbon, “Mixed”, Iron-gall}

Red ink is fairly common on Pharaonic papyri, but almost totally absent from documents of the Greco-Roman period. The presence of red ink precludes the use of red filtering or infrared which will make reds disappear from the photo, and other methods, like DStretch or in some cases just a green filtering to darken the reds, must be used. Although it is not an ostracon, but a dipinto on a wall, a good example of what DStretch can do is from the sanctuary at Sikayt (Fig. 1). ${ }^{6}$ See more in 5.7 .1 below.

Carbon ink does not reflect red or infrared and thus gives the best results with red filtering or infrared, as the ink stays black regardless of what photographic effects can be brought to bear on the color of the background.

Iron-gall inks are often brownish and do, to a greater or lesser extent, reflect red and infrared and must therefore be treated differently.

Since we are on the subject of ink, a special variety must be mentioned, although it does not have any practical relevance for photography, namely inks that contain lead. ${ }^{7}$ Another special case are the "mixed inks" 8 which show characteristics of both carbon and ferro-gallic ink. The photographic treatment of such inks must depend on their color.

\footnotetext{
6 See Cuvigny 2007, 342-343.

7 Brun et al. 2016 and Tack et al. 2016 both describe and analyze a surprisingly high concentration of lead on two fragments (the same in both articles) of carbonized Herculaneum papyrus. This does not seem to be what we normally call "metallic ink", since these are understood as mordant, ferro-gallic inks. The analysis does not mention iron and copper is not found in the ink. No explanation of the presence of lead is found.

8 See Christiansen 2017.
} 


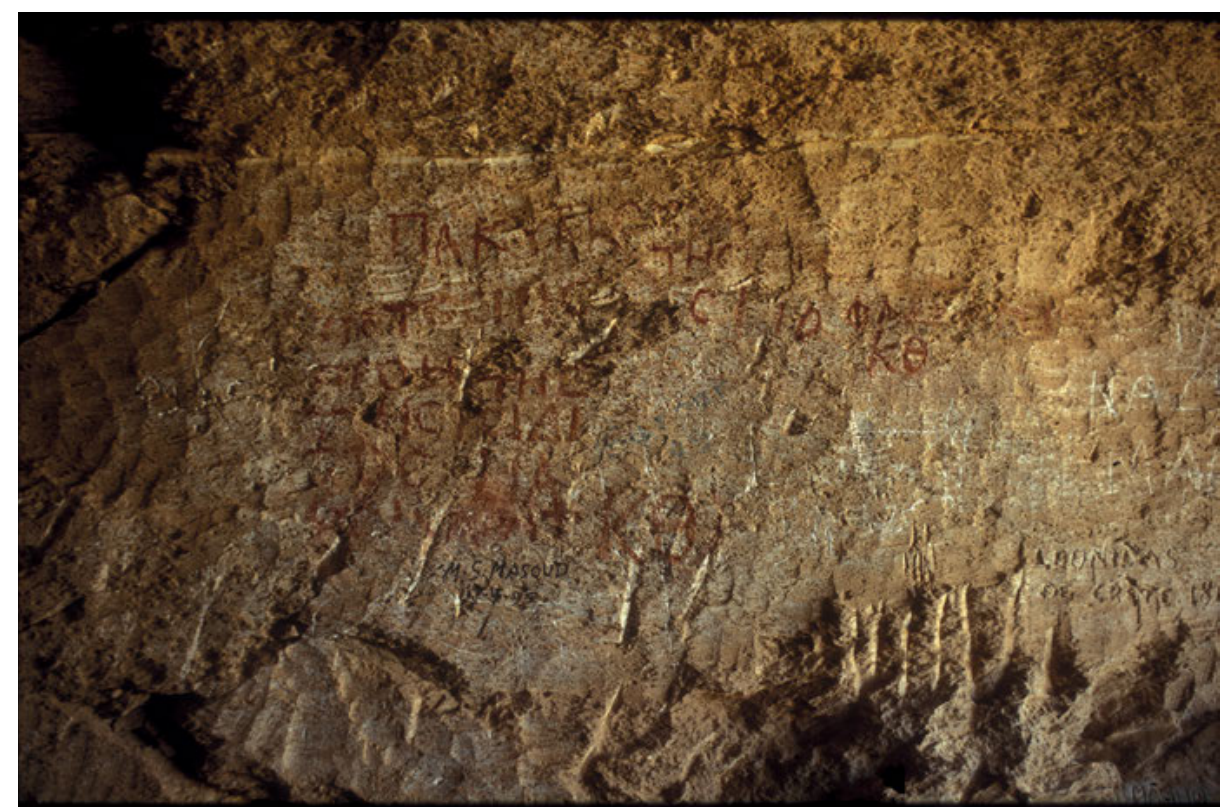

a

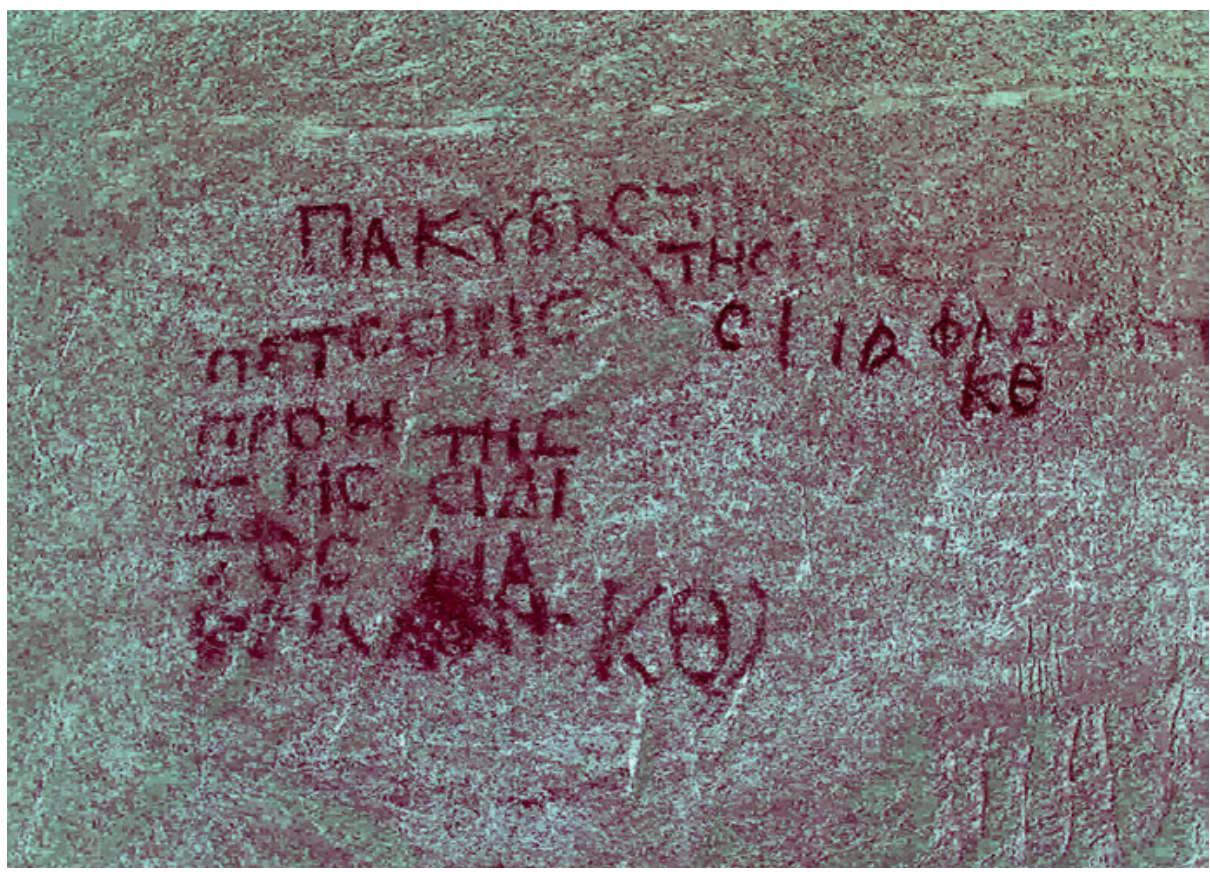

b

Fig. 1: (a) A color slide of a red-paint inscription in Sikayt (Smaragdus) and (b) a DStretch treatment of the same. 


\subsection{Incised Texts}

Incised texts include what we normally call inscriptions on stone, but also scratchings on walls and ostraca. Common to these is that color is irrelevant, and the only way to enhance them is by raking light. Such directional light at a low angle to the surface is easily arranged on a flat, even surface, but very tricky if the written surface is curved, waving or otherwise uneven.

Another problem is that such light will often be too close to the object and thus be uneven across the photograph. If possible, sunlight or directional daylight, e. g. from a window, is very good, if the object can be turned to an ideal angle to the light. With stone inscriptions this will often be impossible, and you may have to wait until the sun is in the right position, if you are working outdoors. When conditions allow, a flash is ideal for raking light, but be sure to have it far enough away, so that the light across the object is as even as possible. Of course, you need to be able to detach the flash from the camera and to have a synchronization cable long enough (and somebody to hold the flash). Also, the flash needs to be fairly powerful, so that it will give sufficient light at a distance of several meters. Depending on circumstance, the ideal solution for incised objects may be the RTI (reflectance transformation imaging). ${ }^{9}$

\subsubsection{Wax Tablets}

Wooden tablets covered with a layer of wax into which letters were scratched were a very common support for writing in antiquity. They present numerous problems for the photographer: the wax has in some cases completely disappeared, and only the scratches of the hard stylus into the wood below remain. In other cases some wax is preserved. The wax will mostly be black, so even if you can get good shadow-effects with raking light, you will be trying to make contrast between black and black. RTI will often be the best (or only) way to handle wax tablets. The RTI-technique consists in making several (e.g. 12 or more) exposures with the object and the camera in exactly the same position while moving the light-source. The exposures are then processed in a program which will choose the optimal lightening for every pixel. ${ }^{10}$ (Fig. 2 )

See more on RTI below, 5.7.3. Advice: If you want to use RTI, be sure to try it out first. The program and the procedure take some getting used to.

9 See 5.7 .3 below. RTI photography is described at http://culturalheritageimaging.org/Technologies/ RTI/ (last accessed: 16.1.2020) where the necessary software (free) and various accessories (not free) can be obtained, as well as courses in the use of RTI.

10 The example shown in Fig. 2 is published in Redon 2016. 


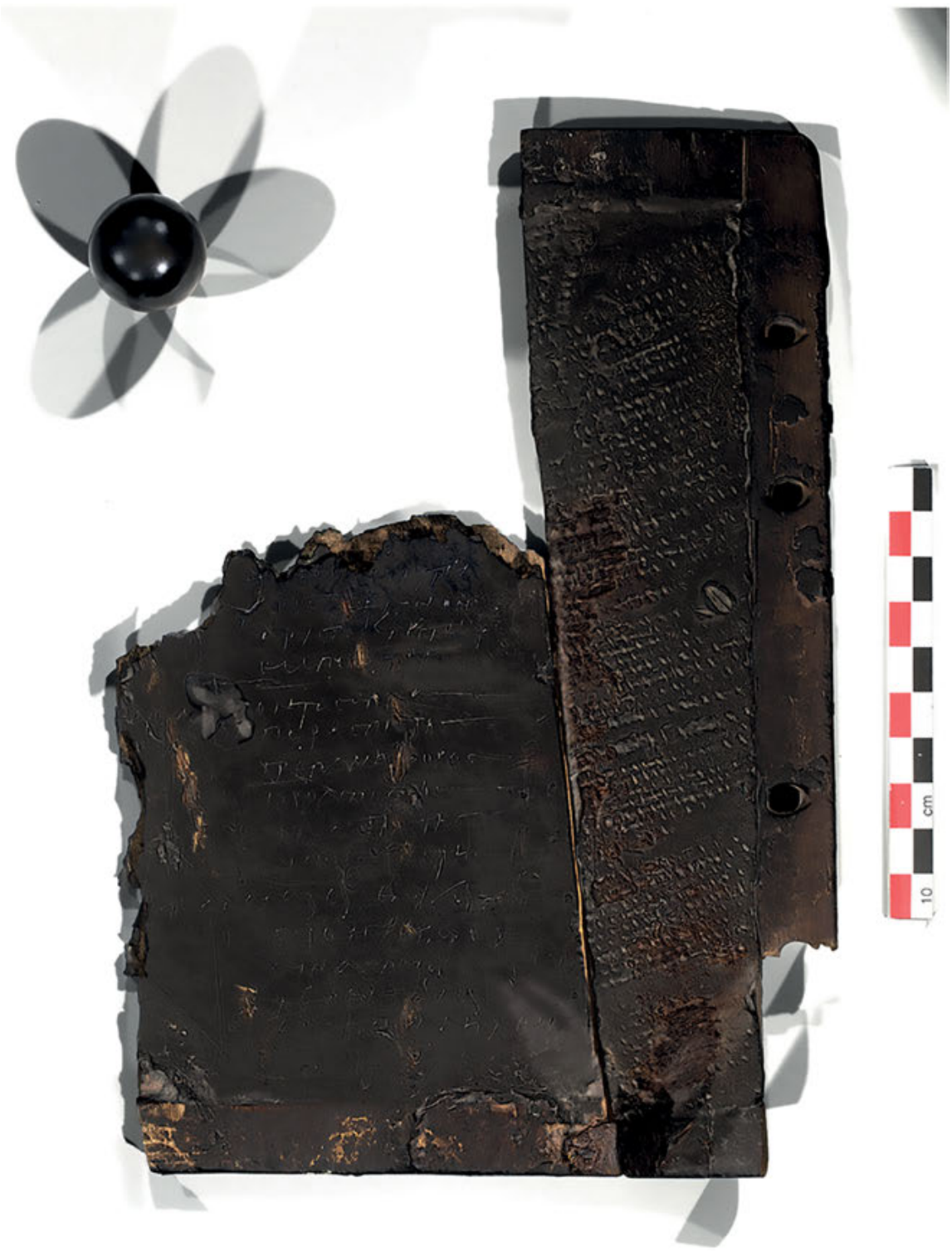

a

Fig. 2: RTI of a wax tablet in Musée des Beaux-Arts in Lyon. The two photos show the same set of exposures in default treatment (a) and in the specular enhancement mode (b, opposite page). Notice the brilliant black ball which indicates the direction of the light in the individual exposures. 


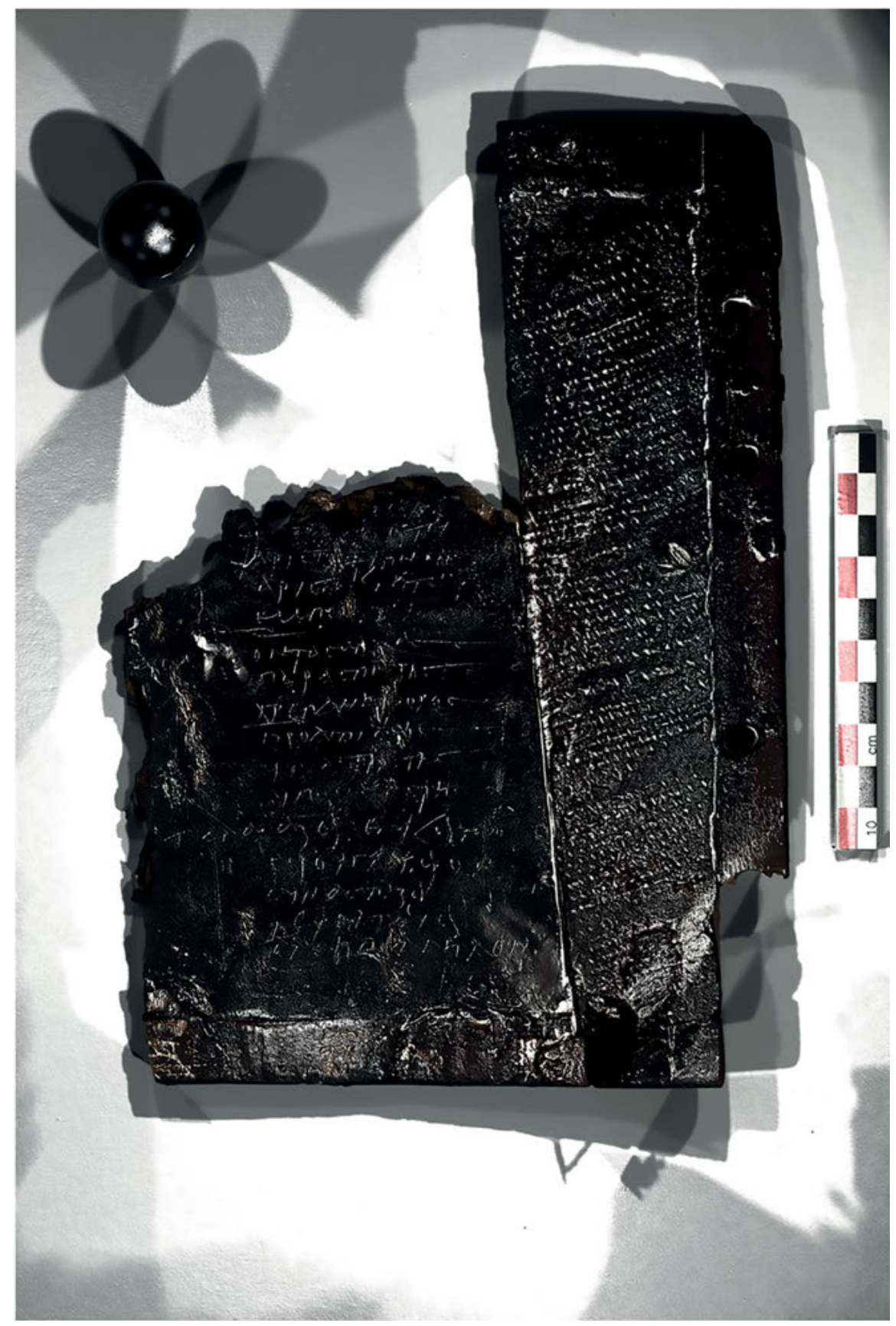




\section{Objectives: What Is It We Want?}

First of all, we do not want a photograph that looks like the original. We want it better than the original from the point of view of reading. This means that we want the highest possible contrast between the ink and the support/background, while we normally have to give a lower priority to the fiber-structure. Of course we want a sharp picture of high resolution which will permit enlargement. Those who work with flat-bed scanners normally set the resolution to $600 \mathrm{dpi}$, which is not always possible to obtain when working with a camera, if the original is big. But the minimum requirement is $300 \mathrm{dpi}$ at natural size, which permits printing, and which also permits 4-times enlargement on the screen. A scale next to the papyrus is essential.

You can work in color, but with all the necessary manipulations, the colors become an embarrassment. So, unless the original is perfect and needs no treatment, I normally try to produce a good black-and-white print.

\section{Set-up}

\subsection{Staging Your Object}

In the technical literature on imaging the aesthetic aspect of our photographs is understandably neglected and the papyrologist-photographer will most often think only of legibility. There is a distinction often made in archaeological photography generally, between field-photography and publication photography. The thinking behind this distinction is valid enough and very clear in archaeology: In the course of the excavation the archaeologist will want to document details of his work, but from time to time a publishable photo is needed. Foot-prints are removed, scales are put in place, and one waits for the moment when the light is at its best, often early morning or late afternoon, when the sun is not directly on the scene. Perhaps a larger camera with better resolution is used. Until recently this meant a view-camera operated by a professional photographer, but most archaeologists nowadays are able to take such photographs with a medium or high-end digital camera. Ceramics and small finds are a different proposition and will mostly demand some staging, light-setting, and close-up work that the archaeologists may not have the time or the patience to do properly.

The papyrologist will mostly be interested in legibility. He/she will often have access to the piece in a collection where conditions for photography are less than optimal, and with few exceptions the papyrologist will not bring with him the necessary equipment nor be welcome to set it up in the middle of a reading room. So papyrologists often use hand-held cameras and available light, which may solve the immediate problem of getting a useable record, but not necessarily make a publishable photograph. 
The set-up, lighting, background etc. are treated below. Papyri are easy since they are two-dimensional: place them squarely under the lens and do not waste too much space around the edges (i. e. get close enough), remember the scale and be sure it is parallel to the edge. Labels for identification must not overlap the object.

Ostraca are three-dimensional and more complicated. You will need an arsenal of small props to place the text to its best advantage. Plasticine is useful, but also empty film-canisters, small blocks of wood, and rings cut from transparent plastic tubes make good props. Whatever is small enough to hide behind the object, so that it is not seen in the photograph. ${ }^{11}$ Stopping down to get depth of field may be necessary, but see Section 4.1 below about hot spots when working in infrared. Do not stop down more than necessary since few lenses are at their best at $f 16$ or 22 . Depth of field and optimal sharpness are not the same.

Do not forget to prop up the scale and the label so that they are at the same level as the surface of the object. A scale placed too high or too low will not show the true size of the object and may be out of focus.

Since ostraca are curved, small ostraca are much easier than big ones. Text on the edge of a big ostracon can be extremely tricky to place so that it is at best visibility to the camera. In extreme cases it may be necessary, as a last resort, to hold the fragment in position by hand.

\subsection{Copy-stand}

In most cases we want a dead vertical image in order to avoid distortion. For this, the use of a copy-stand is essential for precise focusing and control of movement. The copy stand allows adjustment of the scale of reproduction in relation to the size of the object and assures that the axis of the camera is at $90^{\circ}$ to the surface where the object is placed. It is thus much faster and more flexible to work with than whatever solutions can be created with a tripod. Furthermore, it leaves you free to illuminate your object from whatever side you want except where the column is, and you do not risk shadows from the legs of the tripod. But reproduction stands are heavy and cumbersome and extremely difficult to transport. ${ }^{12}$ Some tripods can be inverted so that the ball-head points downwards and the height over the object can be adjusted while preserving the vertical alignment. This may work well for a few shots, but must be considered a makeshift solution. The legs of the tripod will get in the way of the light, and if you are photographing a series of objects of varying size, it is very tiresome and time consuming.

11 The first year of working at Mons Claudianus I was not prepared for this and had to use a selection of stones-the only thing available in the desert.

12 In 1978, when I first went to photograph papyri in Egypt, I managed to get a copy-stand there with such difficulty that I left it and profited from it on all the excavations in which I subsequently participated. 


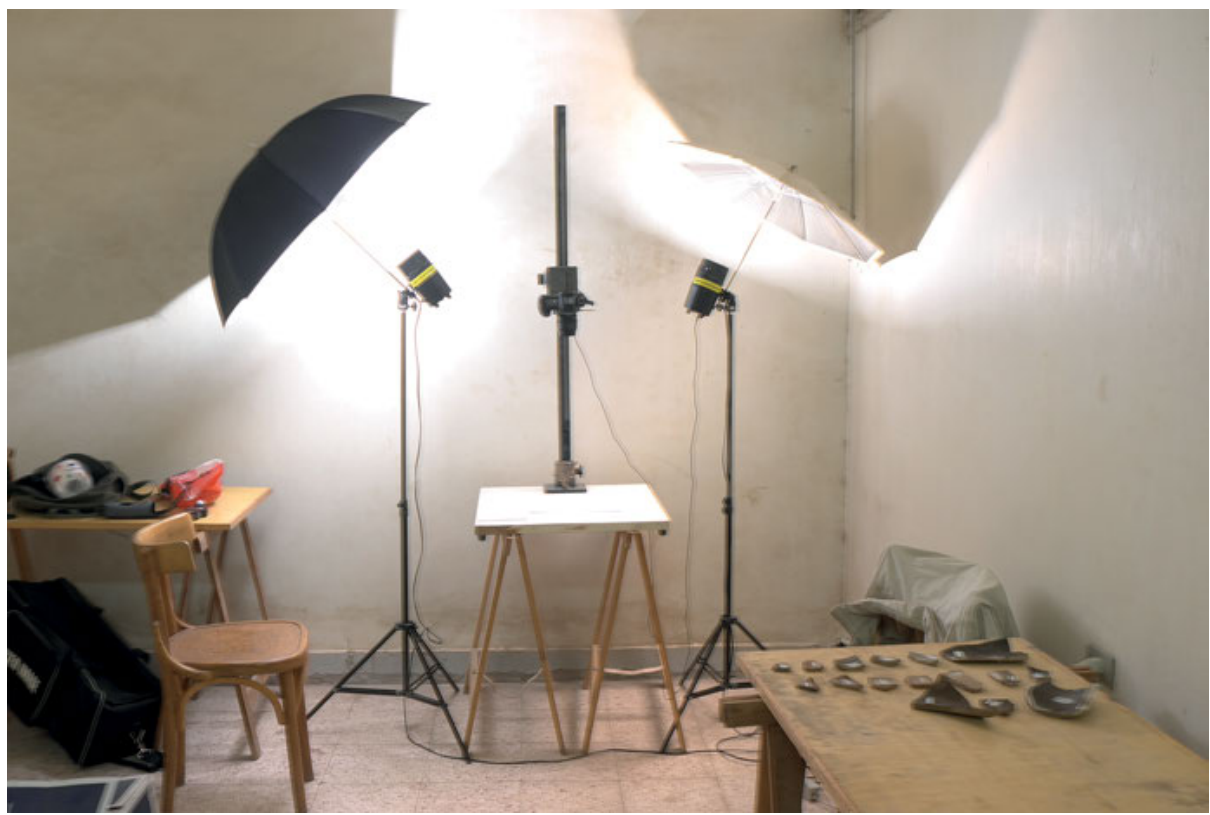

Fig. 3: Typical set-up when photographing ostraca in the storeroom in Egypt: A copy-stand and two flashes with umbrellas, to give even, diffused light. If you are photographing papyri under glass, you will need to remove the umbrellas and turn the flashes directly onto the reproduction-surface, since the umbrellas will almost certainly make reflections in the glass. Here the lights are set at a higher angle than $45^{\circ}\left(c .70^{\circ}\right)$ since there is no risk of reflections.

\subsection{Hand-held}

Because of the difficulty of transporting copy-stands many papyrologists prefer to hold the camera free hand. This is of course possible and has yielded good results, but there are limitations. The very high ISOs that can be obtained with modern digital cameras permit short exposures with available light. If you are working a whole day taking photographs like this, you will find that it strains your back and that a certain number of your pictures are less good than they would have been if you had used a copy-stand. 


\section{Focusing and Exposure}

With the advances of auto-focusing on modern digital cameras, the art of focusing has been all but forgotten. Furthermore, papyri are flat, two dimensional objects and depth of field is not really important. Ostraca, being three-dimensional, present more of a problem: they are most often curved and need depth of field, and often you need to take several shots to get a good view of all the writing. Depth of field will normally be a simple question of stopping down. But see 4.1 on stopping down when working in infrared.

\subsection{Focus and Exposure with Infrared}

Focusing when working with infrared used to be a problem in the days when you used a special infrared film and a normal camera. Infrared light has longer wave-length than the visible rays and focusses at a point behind the film/sensor. In other words, if you focus on the visible image on the mat screen of your SLR or view-camera, the infrared picture that you take will be out of focus, and to correct this you must either extend the focal distance (between the lens and the film) or the distance between the lens and the object. Knowing how much to increase was a matter of experience unless you had experimented and made yourself a scale of how much to correct at any given distance. All this is now history, since digital cameras, when they are converted to infrared use, are also adjusted to focus correctly for infrared. The new mirrorless cameras solve the problem, since they focus, not on a screen, but on the infrared image itself, and so get the focus right. Another difficulty with infrared is exposure, since infrared light is invisible to the naked eye and also to the light-meter. Visible light may contain more or less, or no infrared light, so there may be surprises. The most important sources of such surprises are treated below in Section 5 .

If you are working with infrared, be aware of the risk of hot spots: some lenses will give a white spot, mostly hexagonal or octagonal depending on the number of blades in your iris-diaphragm. The more you stop down, the more pronounced this becomes. Some lenses are worse than others and if the lens you are using makes unacceptable hot-spots at the aperture you want to use, you must use another lens. ${ }^{13}$

13 The Canon 50mm Compact Macro Lens, which I normally use, cannot be stopped down further than $f 5,6$ before the problem appears. This lens is no longer available Alternatively, I sometimes use a Leitz $60 \mathrm{~mm}$ Macro-Elmarit-R (fully manual) which can be stopped down further before showing hot spots. There is some information on the subject and the reasons on https://www.lifepixel.com/lensconsiderations (last accessed: 16.1.2020). A database concerning the performance of many different lenses may be found at https://kolarivision.com/articles/lens-hotspot-list/ (last accessed: 16.1.2020). 


\section{Light}

\subsection{Co-axial or Angled Light}

Normally reproduction photography, and so papyri, demand even light from both sides. Such light will flatten shadows and will not bring forward e.g. the fiber-structure in a papyrus. In some cases when shadowless light is especially wanted, you can even use co-axial light, e. g. from a ring-flash or by putting your light-source very close to the camera. ${ }^{14}$ Surprisingly such light is often used for coins when they are properly cleaned and on occasion it has worked well on incised wax tablets. In any case, if the object is under glass, co-axial light cannot be used.

Papyri under glass must be illuminated with light at $45^{\circ}$ so that reflections are not seen by the camera.

Incised objects may often come out well just by turning off one of the lamps, but may require that the light be set at a lower angle. Remember to adjust the exposure.

\subsection{Flash, Umbrellas or Not}

If you illuminate by flash, as I mostly do, it gives a softer light if you bounce the flashes into an umbrella or through a soft-box. This can be highly recommended for ostraca. If the object is a papyrus under glass, you will find it difficult or impossible to avoid visible reflections in the glass, and you must remove the umbrellas and point the flashes directly at the papyrus. Flash illumination has several advantages:

1) It gives you a very short exposure and thus eliminates any risk of a shaken picture.

2) It has a daylight quality and can be used without correction for color film or digital color exposures.

3) It contains plenty of infrared rays.

4) And it does not give off heat. This latter point will be appreciated if you have ever worked with $500 \mathrm{~W}$ lightbulbs in a confined space or a hot climate.

\subsection{Tungsten}

Incandescent glow-lamps are excellent for illuminating a photograph. The ordinary, household variety give a reddish light $\left(2800 \mathrm{~K}^{\circ}\right)$ and are not ideal for color photography, but hypertension lamps, so-called B-lamps $\left(3200 \mathrm{~K}^{\circ}\right)$ or A-lamps $\left(3400 \mathrm{~K}^{\circ}\right)$ used with calibrated film could give excellent results. All this is now history. Incandescent lightbulbs are being phased out since 2009 because of new regulations, and specially

14 The use of co-axial light is treated at length, and in very technical language, in Nurminen 2011. 
calibrated film is no longer produced for lack of need. On a digital camera, one just has to set the white balance. If you work in color with incandescent light-bulbs and set the white-balance accordingly (i.e. on white paper illuminated by the incandescent bulbs), remember that you must exclude ambient (day)light. If you do not, you will get blue shadows because the shadows receive a higher percentage of ambient light than the highlights. But in the modern world this situation is unlikely to occur.

\subsection{LED, Fluorescent Tubes, Economy Bulbs}

The disappearing glow-lamps are being replaced by a variety of excellent new forms of light. Flash has been mentioned, but is of course not useable for moving pictures. You will often find that fluorescent tubes are used for reproduction, and in scientific set-ups for RTI or multispectral photography LEDs are now widely used. Halogen lights are excellent for photography, while the economy-bulb, in spite of much improvement, is still not useful for photography. Excellent LED-arrays are commercially available for moving pictures and can also be used for stills. Common to all these light-sources is that they are meant to give visible light. In fact, the economy for which they are designed is obtained because they do not emit infrared light and heat. So, especially if you are working with infrared, whenever you use light-sources that you do not know in advance, be careful to test how they work with infrared. The lights may emit much less infrared than you expect, and very often none at all.

Infrared LEDs exist, but will not normally be part of an off-the-shelf array. Fluorescent tubes never, in my experience, emit infrared rays. So, if you are working in infrared, use flash or old-fashioned incandescent bulbs, if you can find them, or halogen lights.

\subsection{Daylight}

Daylight is excellent for all kinds of work including infrared. Try to avoid direct sunlight which throws very hard shadows. The drawback with daylight is that it is often found out of doors, where there is also the wind that blows away your labels, and that you cannot direct or regulate it.

\subsection{Background}

When a photograph of a papyrus or an ostracon is published, it is normally "scraped free" (in French: détouré) which means that anything around the object, especially shadows, has been removed. In the days of film, this was done by the print-shop: the graphic negative with screen from which the printing plate would be made was placed on a light-table and the craftsman would paint around the object with red paint, thus 


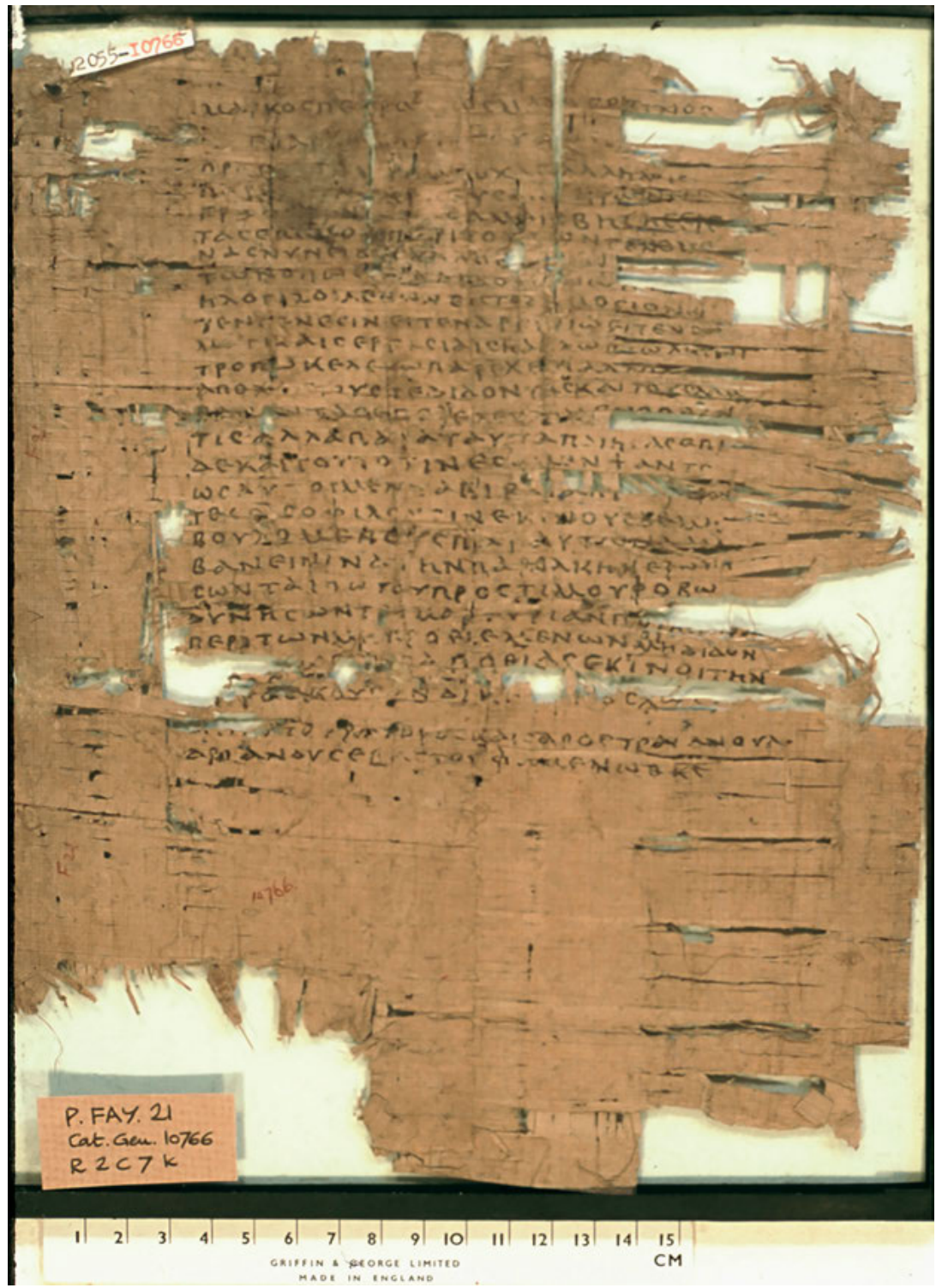

a

Fig. 4: These two photographs of P.Fay. 21 will illustrate the issue. The papyrus is mounted "clear". The color photo (a) was taken directly on a white background (on $35 \mathrm{~mm}$ film) while the blackand-white (b, opposite page) was lifted from the surface below $\left(4^{\prime \prime} \times 5^{\prime \prime}\right.$, with orange filter, not on a light-box which I did not have in Cairo, but the effect is similar). The difference is striking: on (a) you do not see that the vertical fibers on the back are completely stripped away on the right side of the papyrus. All the holes and cracks are seen as black and are indistinguishable from ink. Both photos are from the AIP archive, downloadable from the Centre for the Study of Ancient Documents http://ipap.csad.ox.ac.uk/4DLink4/4DACTION/IPAPwebquery?vPub=P.Fay.\&vVol=\&vNum=21 (last accessed: 16.1.2020). 


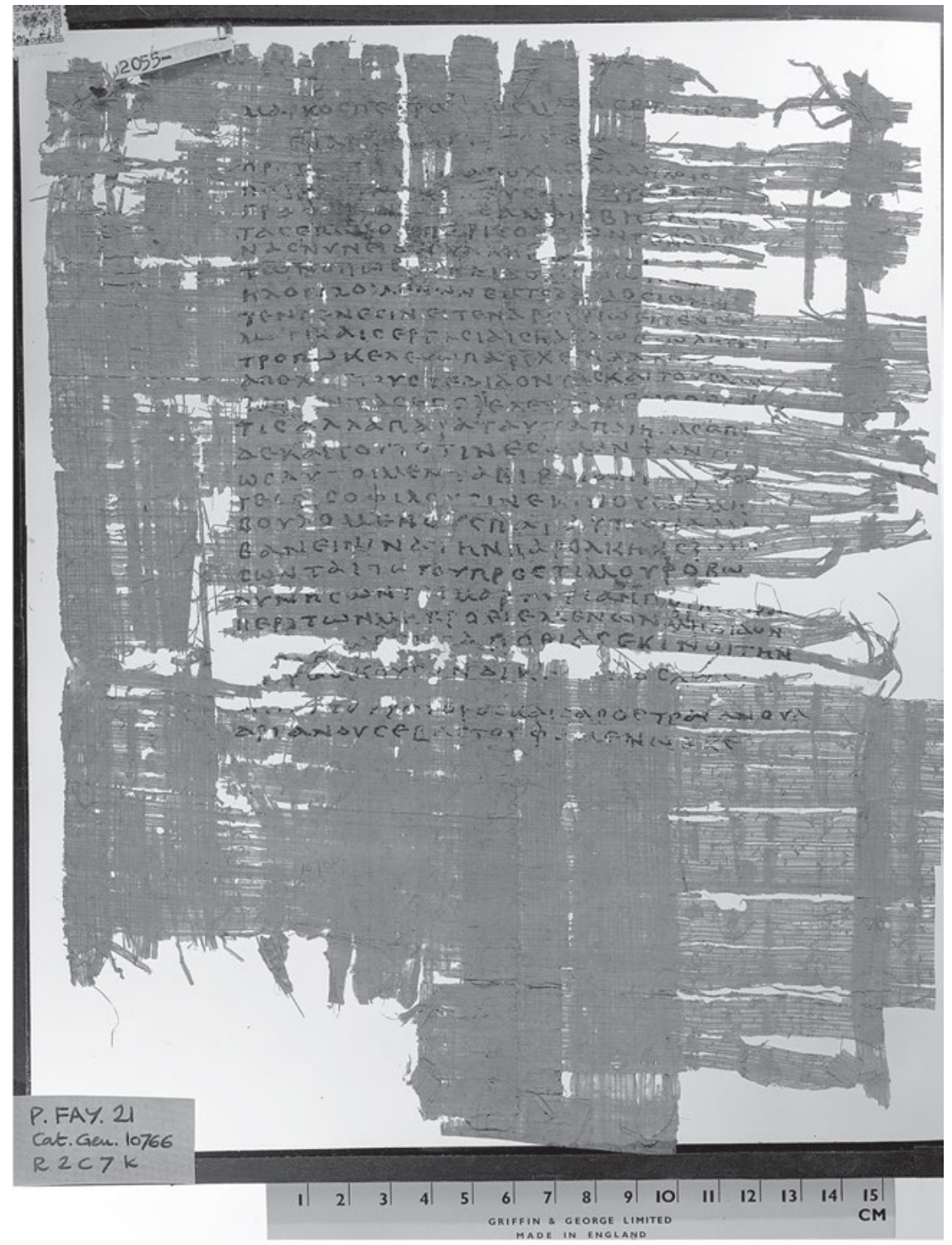

b

painstakingly blocking out everything but the papyrus (or whatever). On a torn and holed papyrus this was a lengthy and difficult job that was open to many errors. Nowadays this is all done electronically, but still involves a certain amount of manual work. Whether it is done with a brush on a light-table or on a computer screen, the operator (or the computer-program) needs to follow the circumference of the object as it is defined by the contrast between background and papyrus. Since a good blackand-white photograph of a papyrus shows the papyrus as light grey, the ink as black 
and the background white, this can be tricky where there are frayed edges and holes. The easy way for the photographer is to place the papyrus on a black background. ${ }^{15}$ While the black background eliminates shadows, it also makes it impossible to distinguish the difference between a small hole and a speck of ink. So, in spite of some advantages, the use of a black background must in all circumstances be avoided.

The best way to obtain a good reproduction of a papyrus is to place it on white blotting paper between two sheets of glass. The reason why this is not always done is that the back of the papyrus is invisible, and most papyri are therefore mounted "clear" between two sheets of glass. When a papyrus mounted this way is photographed on a white background there will be shadows around the edges due to the distance (normally 2-3 $\mathrm{mm}$ ) between the papyrus and white paper which is created by the lower sheet of glass.

\subsubsection{Light-box?}

The obvious solution to the problem of the background is to photograph your object on a light-box, and this can work well, but great care is needed. If you work with still lights (i. e. not flash) the light from the light box will very often be too strong and the result will be an underexposed, transparent image of the papyrus. Except for the transparency, the result will be the same with an ostracon. Some light-boxes can be dimmed which offers a solution: start at minimum and increase the light until the shadows begin to disappear. If your light-box cannot be dimmed, you may put sheets of white paper on the light-box under the object. To decide the exposure, turn off the light-box and measure either by incident light or on an $18 \%$ reflection grey card.

If you are working with flashes, you can profit from the fact that the exposure is dependent on the aperture only. Do as follows: turn off the light-box and determine your aperture. Then, without changing this aperture, make a series of test shots at various exposure times until you find the ideal combination where the papyrus is well lit, but not transparent, and the white background does not show any shadows. Once you have this worked out, note it down and use the same set-up next time. As an example, I used to have a set-up where the exposure was $f 11$ and the time $1 / 30$ or $1 / 15$ depending on the thickness of the papyrus. ${ }^{16}$

If you are working in color, the mixture of the flash-light and the fluorescent tubes of the light-box may be a problem if you are very critical.

15 Regrettably this is still done by some collections, not least the British Library.

16 This was working with large-format film where one often uses smaller apertures. Theoretically you may find yourself needing a shorter exposure-time than the flash-synchronization of your camera allows. Turn up the power of the flashes, if this is possible; if not, move your flashes closer (not too close), or dim the light-box with paper. 
And then the great drawback: All light-boxes I have ever known are illuminated by fluorescent tubes or similar light, which has no infrared emission. ${ }^{17}$ So, if you are working with infrared, you must forget all about light-boxes. They just do not work.

\subsection{Special Tricks}

\subsubsection{Photographing Ostraca Wet or Immersed}

If you have ever treated ostraca on an excavation, cleaning and restoring them, you will know that they often become more legible when wet, whether from water or alcohol. It is tempting to try to use this effect when photographing, but you will find that it is almost impossible to avoid hot-spots from reflections. A work-around is to place the ostracon in a shallow dish-e.g. a deep development dish-and cover it completely with water. This way you will get the effect of the wetness, while the surface of the water will act in the same way as glass, i. e. the reflections can be avoided with lights at $45^{\circ}$. The method has many drawbacks. (1) You must make sure that the ink does not run or dissolve in the water. (2) The mud and sand that will remain on the ostracon will dissolve and dirty the water, and bubbles will develop on the surface of the ostracon. You may have to change the water several times before it stays clear, and wait for the ostracon to be completely water-logged so that there are no more bubbles. (3) Placing scale and labels next to your object is not possible. (4) It is disagreeable to work the camera with wet fingers. (5) Any museum curator who hears what you are about to do will send you packing.

So this method can only be attempted for site photography where you may still have control over the finds, and only when you have checked that the ink is stable enough to support the treatment. The method can of course be combined with infrared photography.

\subsubsection{Diffused Light for Carbonized Papyri}

Many carbonized papyri are slightly brilliant, while the ink is mat. This can be exploited to make the text legible. ${ }^{18}$ You need to illuminate the papyrus with diffused light directly from above, e. g. by pointing your lights at a low white ceiling. What you get, in reality, is a reflected image of the white surface above, broken by the mat ink. The image is in black and white and it is unnecessary to use infrared procedure. The method cannot be used on papyri under glass.

17 There is no intrinsic reason and it would be possible construct an infrared light-box e. g. with IRLEDs. It may even exist already without my knowledge. But the market for such a box would be very limited.

18 Nurminen 2011 concerns this as well. 


\subsubsection{RTI}

Reflectance Transformation Imaging ${ }^{19}$ is an effective way of bringing out surface-structure in anything incised, like inscriptions or graffiti, amphora stamps, coins, wax tablets ${ }^{20}$ and can also be used to enhance fiber-structure in a papyrus. The method is technically rather demanding, since you must have a completely stable setup, perfect control of the light and you must also have the necessary brilliant black balls by which the direction of the light in each shot is determined by the software.

The procedure is as follows: place the object, the scale, and the black ball(s) on the base-board of your copy-stand. Focus and set the aperture. A single light (flash can be used) is then placed at various angles and directions around the object. In practice, you either need a remote release or an assistant to press the button, while you manipulate the lighting. Depending on the nature of the object, eight to twelve exposures should be enough. Place the light from four or more different directions around the object and from very low, raking light to oblique from a higher position. Since it is important that the aperture stays the same, remember that the lower the light, the less it illuminates. At angles lower than $45^{\circ}$ (i. e. lights are placed lower relative to the illuminated surface), you may need to add one or two light-values (don't touch the aperture!). In practice, working with flash, measure your light with the flash in a low position and place it farther away from the object when it is at in high position. If you are using still light, you can set your camera on "aperture priority" and let the shutter decide the exposure. In this case, you need to make sure that ambient light does not interfere. When you have acquired your images, you load them into the RTI-builder program (free, from $\mathrm{CHI}$ ) and the program will analyze, pixel by pixel, where the best angle of light is. You may thus see that certain parts of the finished image seem to be illuminated from the right, others from the left. The images can be viewed in the (free) program RTI-viewer which allows you to move the light virtually and to take snapshots in jpg of your preferred results.

The RTI-procedure needs practice, so make sure that you master it before finding yourself in need of it. Make sure that you have the brilliant black balls (can be purchased from CHI) since they are difficult to improvise. ${ }^{21}$

I have described here how to use RTI on objects that are best treated on a copystand, but of course it can equally well be used on walls or bigger inscriptions or reliefs with the camera on a tripod. ${ }^{22}$

$19 \mathrm{http}: / /$ culturalheritageimaging.org/Technologies/RTI/ (last accessed: 16.1.2020).

20 See Section 1.5.1, above.

21 I have once used the bottom of a round pipe, and have seen results (unsatisfactory) from using a ball of plasticine.

22 The kit that you buy from CHI contains various means of placing the black ball relative to a vertical surface. 
I have never had occasion to try, but there is no reason why RTI should not be combined with infrared or any other filtering, if e. g. the object is an ostracon with both incisions and ink.

\subsubsection{DStretch}

An entirely different approach is DStretch which is a plugin to be installed in the specialized image-treatment program ImageJ. ${ }^{23}$ Both the program and the plugin are free. The plugin is designed for enhancing paintings on rock-faces that are very often extremely faded, and its most spectacular results are obtained with red or yellow pigments. Contrary to Pharaonic papyri, red colors are fairly rare in the Greco-Roman papyri and ostraca, but there are cases when DStretch becomes indispensable. In fact, whenever infrared is worse than useless, i. e. when the details you want are red. The example shown here (Fig. 5) is from the big column on Mons Claudianus, where we had always been aware that there was something written in red on the end, but could never really work it out.

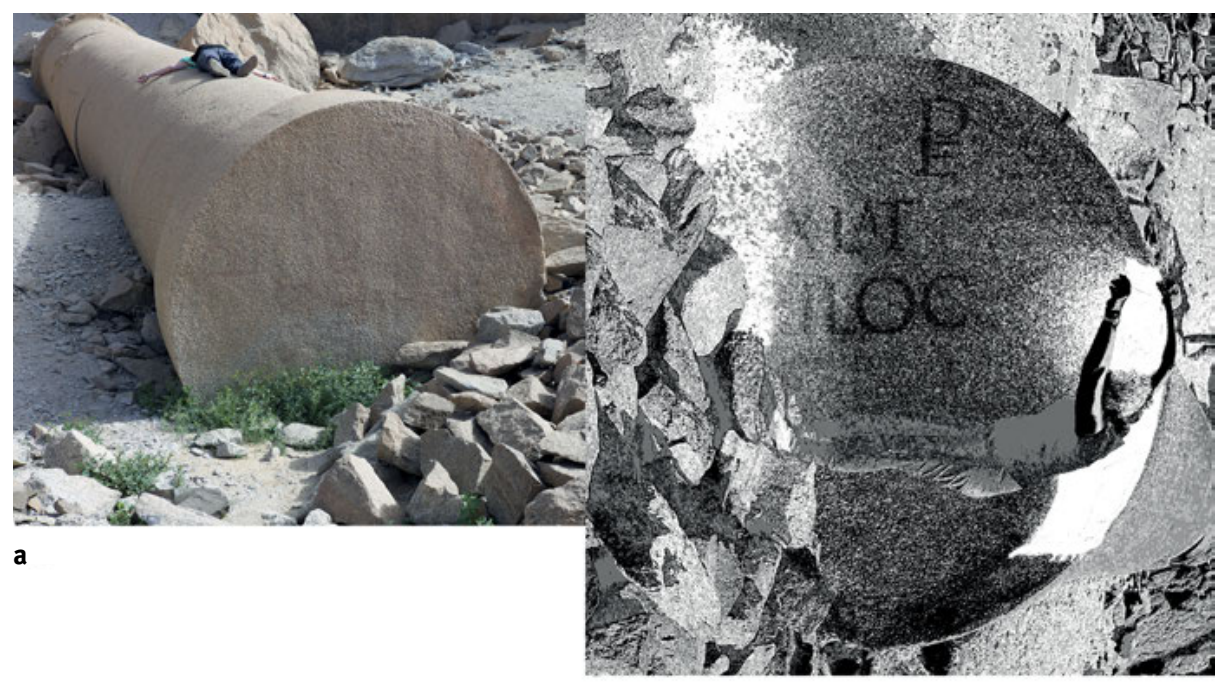

b

Fig. 5: The end of the giant column at Mons Claudianus. Ordinary color (a) and DStretch (b).

23 See http://www.dstretch.com (last accessed: 16.1.2020) for instructions, description, and the address where you can obtain it. 
Using a green filter to darken the red helped a little, but not enough. A photo was taken with the inscription shaded from direct sunlight. This was turned $90^{\circ}$ to get the text the right way up and put through DStretch (the LRE button ${ }^{24}$ ). This brought out the reds very nicely. Then the green channel was extracted from the photo to darken the red and finally the contrast was raised considerably. As a result we can now read what is left of the inscription

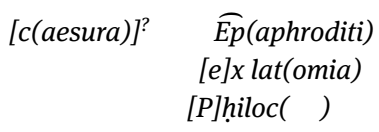

[The caesura?] of Epaphroditus from the quarry

of Philoc $(---)^{25}$

Another example of wonders worked by DStretch is a dipinto in the rock-sanctuary at Sikayt (Smaragdus) ${ }^{26}$ which is illustrated in Fig.1, for which see above Section 1.4. From a practical point of view, DStretch is interesting also because it can be applied to already existing color-images. Thus, the original photograph from Sikayt is a slide from 2001. There even exists an app that lets you treat photos directly on your telephone.

\section{Infrared, Red, Color, Blue, UV}

Infrared photography of papyri and ostraca has long been known to be useful. Infrared film was available, notably from Kodak, and "black" filters ${ }^{27}$ to cut out the visible light were put in front of the lens after framing and focusing. In practice, this meant that images were captured at wavelengths between $c .780 \mathrm{~nm}$ and as far as the film was sensitive, mostly to $c .900 \mathrm{~nm}$. Digital cameras are sensitive beyond this, up to c. $1100-1200 \mathrm{~nm}$, but in most cameras a filter is built in to block out the infrared rays. Your cameras must therefore be converted by taking out this filter and replacing it with one that cuts out all visible light and transmits only infrared. ${ }^{28}$ There are several types of conversion on offer for landscape-photography, false color and so on, but for ostraca and papyri you want deep infrared black and white. This conversion filters out

24 This will mean something when you have installed the program.

25 Cuvigny 2018, Section IV.1.90.

26 See fn. 6 above.

27 I mostly used a Wratten 87.

28 Conversions are made by several firms. I have personal experience with: Lifepixel (https://www. lifepixel.com [last accessed: 16.1.2020]) in Mukilteo, WA, USA, and Optic Makario (http://www.opticmakario.de [last accessed: 16.1.2020]) in Mönchengladbach, Germany. 


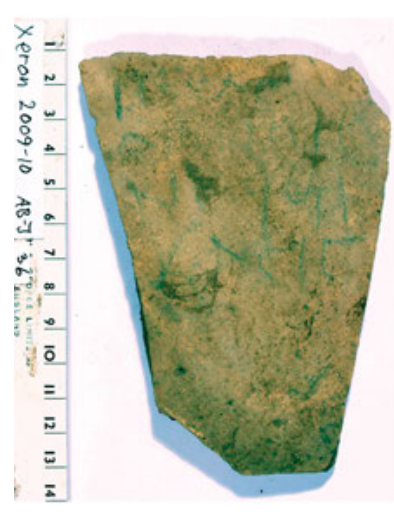

a

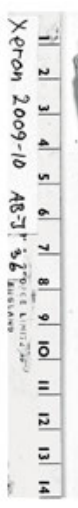

b

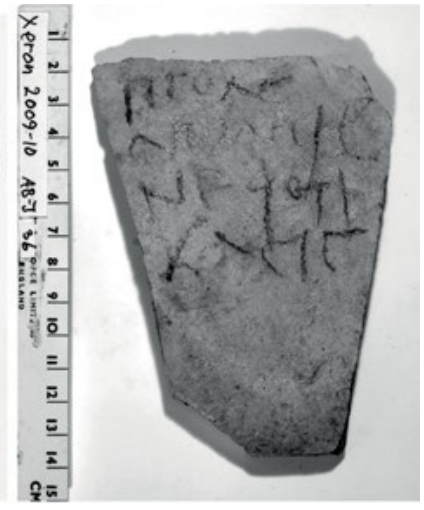

C

Fig. 6: 0.Xer. inv. 36: (a) color, (b) red-channel, (c) infrared.

any light-rays shorter than $830 \mathrm{~nm}$, i. e. ultraviolet and the whole visible spectrum and the nearest part of infrared.

The reason for using infrared on papyri and ostraca is the same as for using a red or orange filter, only more so: the brownish-red surface reflects red only, while the black ink stays black, so the support is rendered lighter, almost white in some cases, and the contrast between ink and background is raised. ${ }^{29}$ While infrared demands special procedure when taking the photo, you will often find yourself with a color-photo of a papyrus or an ostracon sent by a colleague. Such photographs can be improved substantially by making a tricolor separation and discarding the blue and the green channels. Most image-treatment programs can do this. I myself mostly use Graphic Converter, ${ }^{30}$ which has direct application of such a separation, but Adobe Photoshop will also do it, although I find it more complicated there.

The method is simple, fast and in many cases as effective as infrared, as shown by a random example in Fig. 6. The text (a list of names, unpublished) is written in charcoal and is almost invisible to the naked eye. The red channel brings out the ink, while the infrared makes it legible.

The other two channels, green and blue, are not very useful for ostraca and papyri. Green can sometimes help in bringing out red ink, but the price is that the support is darkened. DStretch is much better for such cases (see Section 5.7.4, above).

The blue channel is not useful in any cases that I can think of. If you look at old plates or photographs of papyri, you will often find them unsatisfactory even if they are perfectly sharp. This is due to the sensitivity of old films, which were not red sensitive at all. Compare, as an example, the plate of BGU II 628 (Tafel I, published in

29 For a more technical description, see Bülow-Jacobsen 2008. A much more technical description is Bearman/Christens-Barry 2009.

30 https://www.lemkesoft.de/en/ (last accessed: 16.1.2020) much cheaper than Photoshop. 
1898) with the color scan available at the web-site of the Berlin Museum; ${ }^{31}$ if you save this image and treat it as described above by separating out the red channel, the difference becomes obvious. The photograph was undoubtedly exposed on orthochromatic emulsion, sensitive only to blue and green. Panchromatic film, i. e. sensitive to all colors including red, became available only in 1906.

Ultraviolet light is not interesting in connection with papyri and ostraca, but will be mentioned here anyway, since a certain number of misunderstandings are sometimes encountered. For there are two completely different applications of ultraviolet light in relation to manuscript-photography.

1) For reflected ultraviolet photography you place in front of the lens a "black" filter (Wratten 18A) that permits only ultraviolet light between 300 and $400 \mathrm{~nm}$ (and a small percentage of infrared) to pass. The filter is made of Wood's glass and is quite expensive, and you do not need to buy one. Results are of low contrast and the surface of the papyrus/ostracon becomes rather dark. ${ }^{32}$

2) Ultraviolet fluorescence is quite different. In a darkened room, you illuminate your manuscript with ultraviolet light. It does not have any useful effect on papyri, but is often used on parchment manuscripts. The parchment (or paper) lights up, the ink stays black and legibility is much improved. Many manuscript collections have a small cell screened from daylight and equipped with a Wood's lamp. What happens is that the ultraviolet rays activate the parchment which emits light of a longer wavelength, i. e. in the visible region. To photograph this, you need to place a UV filter in front of the lens to exclude ultraviolet light which would otherwise expose the film or the digital sensor. In some cases it is further useful to add e. g. a green or yellow filter in order to refine the fluoresced light. The fluorescent-light is quite faint and long exposures will be necessary. In any case, neither papyri nor ostraca fluoresce, so I mention the method here only for the sake of completeness.

\section{Multispectral}

Multispectral Imaging, MSI, has been much talked about during the last twenty years. It has also created a good deal of misunderstanding because it has been confused with infrared photography. The principle is that you make a number of exposures of your object with different filters, or better with LEDs of different wavelengths. These images can then be electronically arranged in layers to form a "cube". With the proper

31 P. 7815 R, http://berlpap.smb.museum/02270/ (last accessed: 16.1.2020).

32 Some experiments on parchment are published in Bülow-Jacobsen 1979, Appendix 3, 102-104 and Plates 4-8, available on http://cimagl.saxo.ku.dk/download/30/30Bulow-Jacobsen91-104.pdf (last accessed: 16.1.2020). 
software you can then mix the layers, adopting or excluding wavelengths, even give them negative values, and obtain the most extraordinary results.

The most spectacular results of MSI known to me is the Archimedes Palimpsest, on which all the tools of scientific imagery were brought into action..$^{33}$ But this is a medieval parchment codex.

Papyrus, which reflects only red and infrared, is less responsive to MSI which has mostly been tried on carbonized papyri from Herculaneum. ${ }^{34}$ In fact, as far as papyri are concerned, MSI is often used to mean infrared photography at several narrowly defined wavelengths, sometimes no wider than $10 \mathrm{~nm}$. Among the results the best one is chosen, often around $950 \mathrm{~nm}$. Since $950 \mathrm{~nm}$ nearly always gives the best result, it is thought that if the exposure is made at $830-1100 \mathrm{~nm}$ it will contain both the ideal data, but also others that slightly obscure the best image. ${ }^{35}$ Theoretically, this is certainly true. In practice, it will be important only in very critical cases.

The constituent photographs can be acquired in several ways. The most simple is a digital camera without any filters in front of the sensor, i. e. sensitive to all visible wavelengths plus ultraviolet and infrared, but with a filter wheel in front of the lens. In this wheel you can set filters for the wavelengths you wish to acquire. More sophisticated setups vary the illumination with LED arrays and the whole process can be more or less automated. Whatever method is used, you need a large hard-disk for storing the mass of data. I shall not go into further detail with the image acquisition since I have never personally done it, and anyway, if you are going to try MSI, you will need more specialized information than is within the scope of this article. ${ }^{36}$

Common to all the procedures for acquiring MSI that I have seen is that the image field is quite small, which means that most papyri are much too large to fit into a single image. The problem is solved by "stitching" the individual images, including their possible hot spots. This stitching can be done automatically and should normally not be a problem, but we must not forget Murphy's Law-if anything can go wrong, it will-with the rider that we may never notice that something has gone wrong. In fact, I have always wondered why MSI never seems to be done with a decent field of vision.

33 Netz et al. 2011. A very informative and well-made site is http://www.archimedespalimpsest. org (last accessed: 16.1.2020). Easton/ Christens-Barry/Knox 2011 and Bergmann 2011 concern this project, too.

34 See Bülow-Jacobsen 2008 and the answer to it, Bay et al. 2010. This paper nicely illustrates the terminological confusion around the concept of multispectral photography: Multispectral is here understood as imaging in a very narrow bandwidth around $950 \mathrm{~nm}$, while monospectral is the word used for a broader application of infrared, between 830 and $1100 \mathrm{~nm}$. The two papers are extensively summarized in Macfarlane et al. 2011.

35 See Bay et al. 2010, 215-216.

36 There are several specialized appliances for industrial use of MSI. Just to mention a few that I have seen in action: VideometerLab from Videometer, Denmark, and XpeCam from Xpectraltek, Portugal. 


\section{Cameras and Lenses}

Everyone has his preferences, and the choice of camera and lens may depend on what you happen to have already. If you are thinking of having a camera converted to infrared, look at the list provided by the firm of what cameras they will convert. In any case, if you can, go for a full frame sensor $(24 \times 36 \mathrm{~mm})$ with sufficient pixels. Most such cameras will nowadays have sensors of $24 \mathrm{MP}$ or more, which is sufficient for a 1:1 print (300 dpi) of an original just over A3 size. If the original is bigger than this, it will probably be a roll with several columns and will be reproduced on several plates. Regardless of the number of pixels of a given sensor, remember that a smaller sensor with many pixels is more likely to produce electronic noise.

As for the lens, if you are buying one, choose a "normal" focal length from a respectable brand. Zoom-lenses have become very good, but lenses with a fixed focal length (for some reason usually called prime lenses) are better still. So, go for a 50-60 mm lens which permits close-up focusing, perhaps a so-called Macro lens. A shorter focal length, e. g. $35 \mathrm{~mm}$ for a full-size sensor, can be used, but is more likely to distort the object. This is not a fault in the lens, but a simple optical fact, that the closer you are, the greater will be the difference of distance (percentage-wise) between the center and the edge of the reproduced areas, so along the edges letters, or whatever, will be smaller on the photograph. Many Macro lenses have a longer focal length, e. g. $100 \mathrm{~mm}$. While this is useful in many contexts, it will also force you to increase the distance between the camera and the object and you may find yourself having to climb a ladder to focus the camera.

I myself mostly use a Canon Compact-Macro 50mm which is no longer available. It is a good lens, but it does make hot spots on infrared when stopped down, see Section 4.1 above.

And finally, when considering the overall quality of your images, it must be kept in mind that there is a normal, basic rule of photography that does not apply when reproducing manuscripts, namely the viewing distance. A normal photograph, e. g. of a landscape, will be viewed by the spectator at the distance where he can take in the whole of it without moving the head. In other words, big prints are seen from farther away than small ones. This implies that we accept that small details, which are not perceived by the human eye at the optimal viewing distance, are not rendered with perfect sharpness. Equally, the human eye accepts that details toward the edges are less sharp than in the center as is the case with all lenses, but the better (and more expensive) the lens, the less pronounced is the difference.

These considerations do not apply to the reproductions of manuscripts: regardless whether the original is an A3 size or a tiny fragment, we look from the same distance and with the same attention at the individual details (e.g. letters), be they in the center or at the edge of the image. So, if you are buying a lens, chose the best one that your budget permits. 


\section{After-treatment of IR Photographs}

Once you have uploaded your photograph to your computer you may be disappointed. Your white background is probably grey and the object (papyrus or ostracon) is probably too dark, and though improved, the contrast between ink and support leaves to be desired. The reason for this is that the infrared uses only a small part of the available contrast span, and, consequently, the correct exposure of an infrared image is more flexible than when you use the whole contrast span. The tool you want to use is called "levels" in your image-treatment program.

Three stages of a randomly chosen photograph with the relevant levels-window will illustrate the procedure:

a) The raw photo before any treatment (Fig. 7).

b) The same, but after standard treatment (Fig. 8).

c) The photo after the final touches (Fig.9). For aesthetic reason the hard-black shadow has been removed-here done simply with the eraser-and the contrast has been touched up a little.

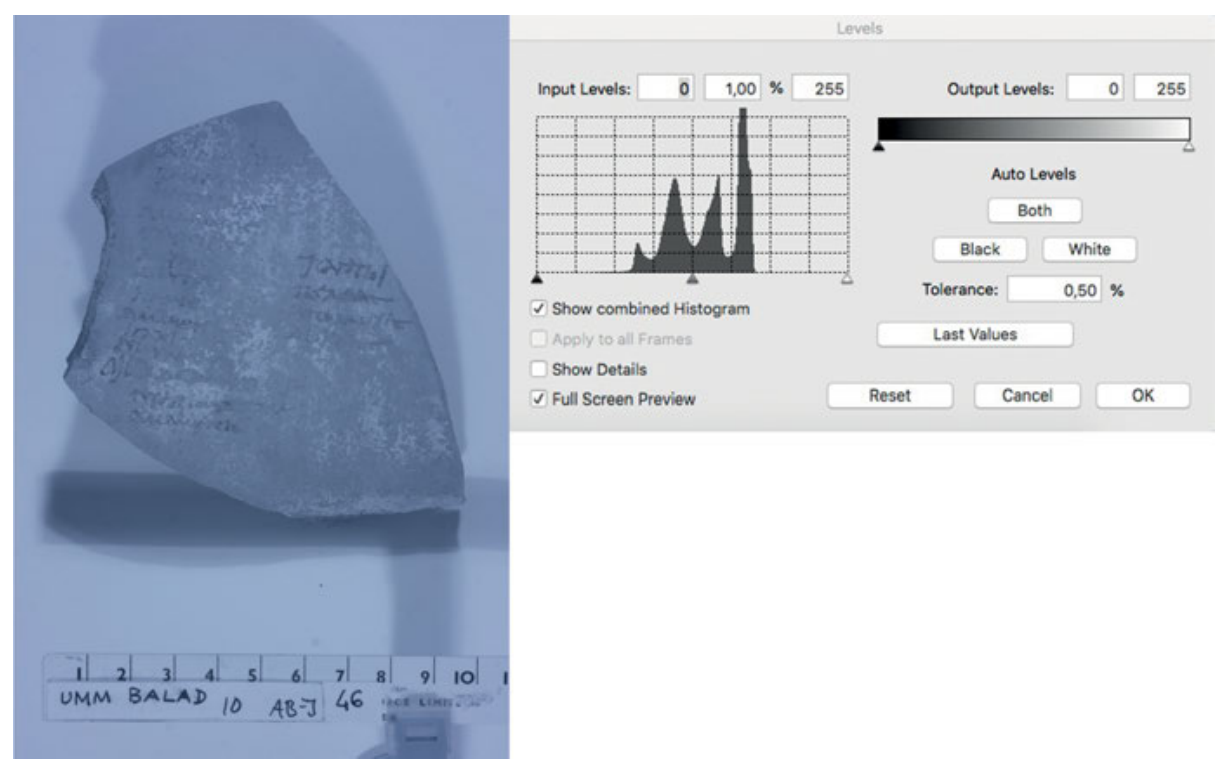

Fig.7: The exposure is set in the middle of the contrast span. The four peaks represent, from right to left, the white background, the light shadows around the ostracon, the surface of the ostracon, and the hard shadow under the ostracon. 


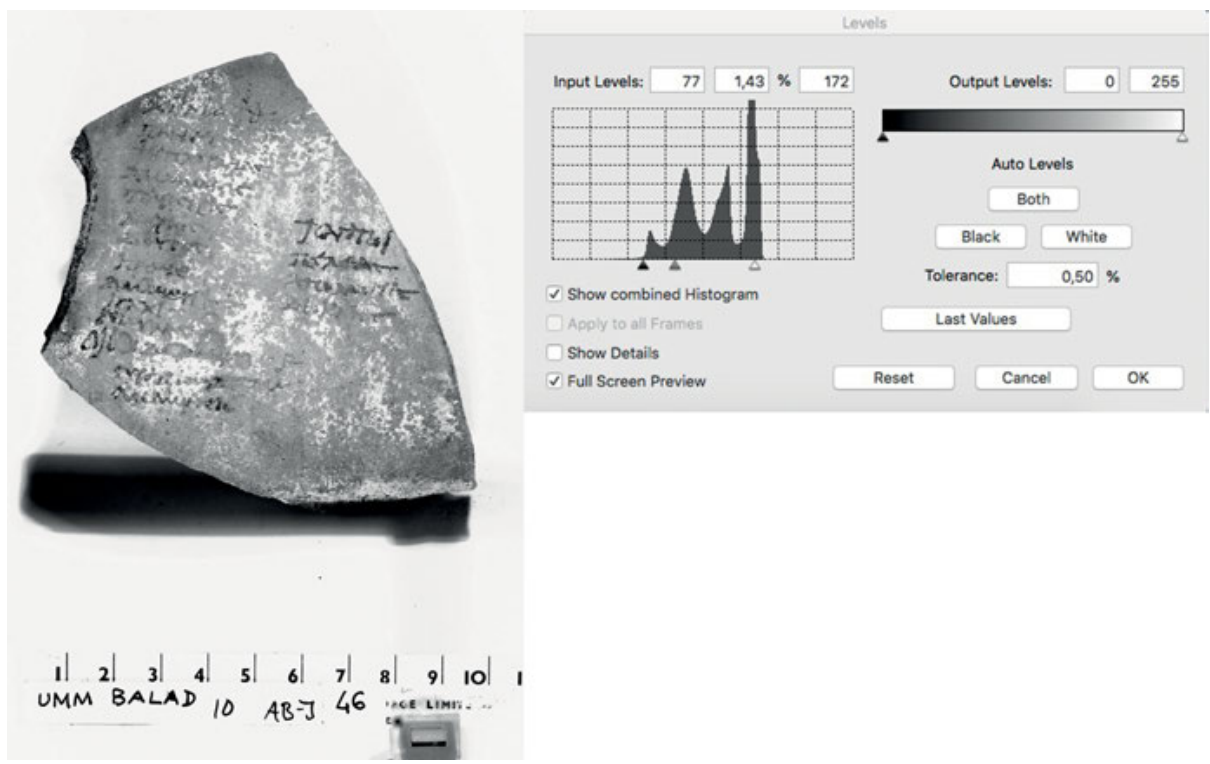

Fig. 8: In most case, just clicking the button "both" will be enough, but you may also move the triangles under the graph. The background is now clear, and the contrast between support and ink is satisfactory. The blue cast, which may be red in other cases, has been removed by reducing the photo to 8-bit greyscale, removing all color.

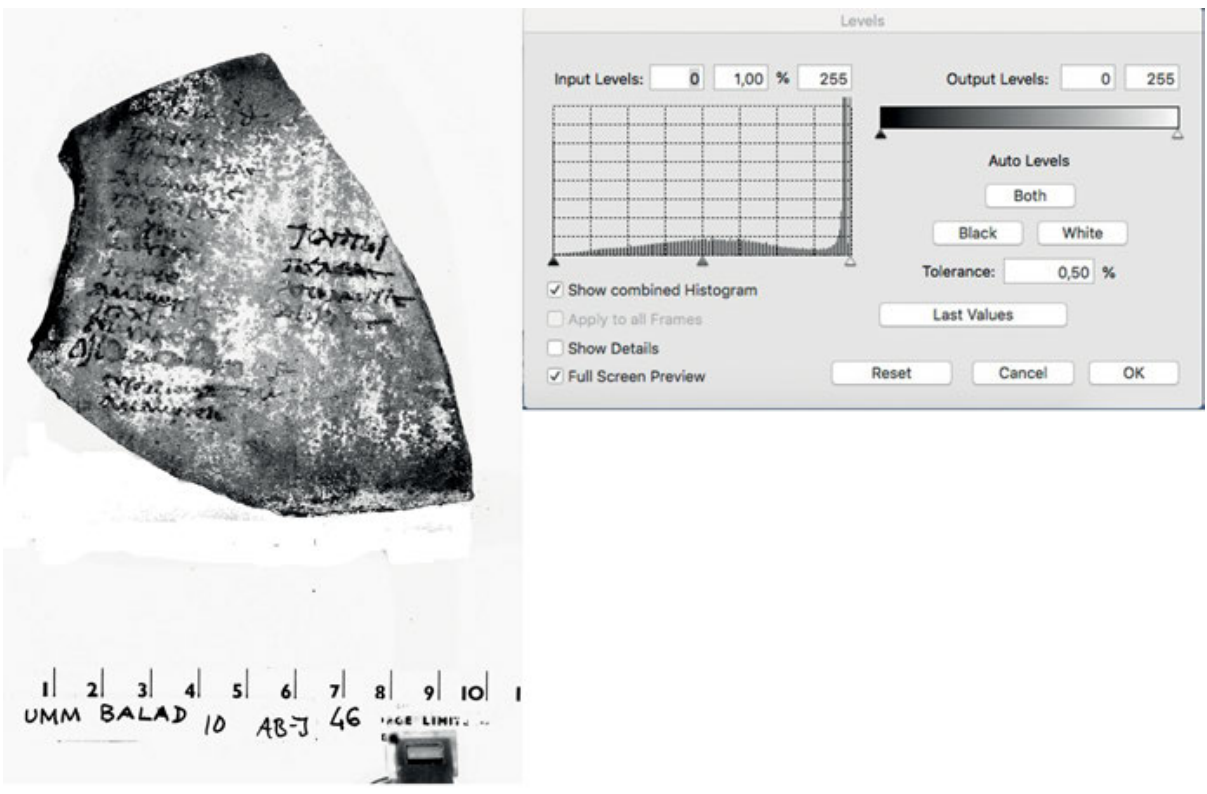

Fig. 9: The levels graph now shows only the white background as a peak to the right. The contrast span has been adjusted to the span of the photograph. 


\section{Bibliography}

Bay, Stephen/Bearman, Gregory/Macfarlane, Roger/ Wayment, Thomas (2010), “Multi-Spectral Imaging vs. Monospectral Infrared Imaging”, in: Zeitschrift für Papyrologie und Epigraphik 173, 211-217.

Bearman, Gregory/Christens-Barry, William A. (2009), "Spectral Imaging of Ostraca", in: PalArch's Journal of Archaeology of Egypt/Egyptology 6 (7), 1-20.

Bergmann, Uwe (2011), "Synchrotron Rapid-Scan X-ray Fluorescence Imaging of Ancient Documents", in: Vena Vahtikari, Mika Hakkarainen and Antti Nurminen (eds.), EIKONOPOIIA. Digital Imaging of Ancient Textual Heritage. Proceedings of the International Conference, Helsinki, 28-29 November, 2010 (Commentationes Humanarum Litterarum 129), Helsinki, 51-64.

Brun, Emmanuel/Cotte, Marine/Wright, Jonathan/Ruat, Marie/Tack, Pieter/Vincze, Laszlo/Ferrero, Claudio/Delattre, Daniel/Mocella, Vito (2016), "Revealing metallic ink in Herculaneum papyri”, in: Proceedings of the National Academy of Sciences 113 (14), 3751-3754.

Bülow-Jacobsen, Adam (1979), "Some Considerations on the Quality of Microfilms of Manuscripts", in: Cahiers de l'Institut du Moyen Âge Grec et Latin 30, 91-104.

Bülow-Jacobsen, Adam (2008), “Infra-red Photography of Papyri and Ostraca”, in: Zeitschrift für Papyrologie und Epigraphik 165, 175-185.

Christiansen, Thomas (2017), “Manufacture of Black Ink in the Ancient Mediterranean”, in: Bulletin of the American Society of Papyrologists 54, 167-195.

Cuvigny, Hélène (2007), "Appendix: Dipinto rouge dans le pronaos du grand temple rupestre de Sikait”, in: Steven A. Sidebotham and Willeke Wendrich (eds.), Berenike 1999/2000, Los Angeles, 342-343.

Cuvigny, Hélène (2018), “La toponymie du désert Oriental égyptien sous le Haut-Empire d’après les ostraca et les inscriptions", in: Jean-Pierre Brun, Thomas Faucher, Bérangère Redon and Steven Sidebotham, (eds.), The Eastern Desert of Egypt during the Graeco-Roman Period: Archaeological reports, Paris, https://books.openedition.org/cdf/5154 (last accessed: 16.1.2020).

Easton, Roger L., Jr./Christens-Barry, William A./Knox, Keith T. (2011), "Ten Years of Lessons from Imaging of the Archimedes Palimpsest", in: Vena Vahtikari, Mika Hakkarainen and Antti Nurminen (eds.), EIKONOPOIIA. Digital Imaging of Ancient Textual Heritage. Proceedings of the International Conference, Helsinki, 28-29 November, 2010 (Commentationes Humanarum Litterarum 129), Helsinki, 5-33.

Macfarlane, Roger T./Wayment, Thomas/Bay, Stephen M./Bearman, Gregory (2011), “Exploring the Limitations and Advantages of Multi-Spectral Imaging in Papyrology: Darkened, Carbonized, and Palimpsest Papyri”, in: Vena Vahtikari, Mika Hakkarainen and Antti Nurminen (eds.), EIKONOPOIIA. Digital Imaging of Ancient Textual Heritage. Proceedings of the International Conference, Helsinki, 28-29 November, 2010 (Commentationes Humanarum Litterarum 129), Helsinki, 107-121.

Netz, Reviel/Noël, William/Tchernetska, Natalie/Wilson, Nigel (eds.) (2011), The Archimedes Palimpsest, Vol.1: Catalogue and Commentary, Vol. 2: Images and Transcription, Cambridge.

Nurminen, Antti (2011), “Illumination Issues in Digitizing Ancient Carbonized Papyri”, in: Vena Vahtikari, Mika Hakkarainen and Antti Nurminen (eds.), EIKONOPOIIA. Digital Imaging of Ancient Textual Heritage. Proceedings of the International Conference, Helsinki, 28-29 November, 2010 (Commentationes Humanarum Litterarum 129), Helsinki, 89-106.

Redon, Bérangère (2016), “Retour sur l'école de tachygraphie d'Antinooupolis. Édition de la tablette MBA-Lyon 1969.487-489 et réédition de la tablette Louvre MND 552J (face avant)", in: Zeitschrift für Papyrologie und Epigraphik 200, 495-510.

Sider, David (2009), “The Special Case of Herculaneum”, in: Roger S. Bagnall (ed.), The Oxford Handbook of Papyrology, Oxford, 303-319. 
Tack, Peter/Cotte, Marine/Bauters, Stephen/Brun, Emmanuel/Banerjee, Dipanjan/Bras, Wim/ Ferrero, Claudio/Delattre, Daniel/Mocella, Vito/Vincze, Laszlo (2016), "Tracking Ink Composition on Herculaneum Papyrus Scrolls: Quantification and Speciation of Lead by X-ray Based Techniques and Monte Carlo Simulations", in: Scientific Reports 6, DOI: 10.1038/srep20763.

\section{Photo Credits}

Fig. 1-3, 4(b), 5-9: @ A. Bülow-Jacobsen.

Fig. 4(a): ( ) R. A. Coles. 